\title{
Review \\ Outcome measures in inflammatory rheumatic diseases
} Jaap Fransen and Piet LCM van Riel

\author{
Radboud University Nijmegen Medical Centre, Department of Rheumatology, 6500HB Nijmegen, The Netherlands
}

Corresponding author: J Fransen, j.fransen@reuma.umcn.nl

Published: 14 October 2009

This article is online at http://arthritis-research.com/content/11/5/244

(c) 2009 BioMed Central Ltd
Arthritis Research \& Therapy 2009, 11:244 (doi:10.1186/ar2745)

successful treatments in the past decade. For diseases for which there already was effective treatment available, new, more effective or less toxic treatments have been tested and introduced [1]. For diseases for which there was no effective treatment, new treatments have been developed and shown to be effective [1]. A well-known example of this is anti-tumor necrosis factor for the treatment of rheumatoid arthritis (RA) and ankylosing spondylitis. The ultimate goal of pharmacological treatment in the inflammatory rheumatic diseases nowadays is to reach and sustain remission, including the complete suppression of inflammation and pain and the prevention of excess disability and organ damage. However, sustained remission, not to mention cure, is still difficult to reach.

The objective of this review is to describe recent developments in outcome measurement for inflammatory rheumatic diseases for trials and clinical practice, with an emphasis on RA.

\section{Outcomes in rheumatology Multiple outcomes}

Inflammatory rheumatic diseases are generally multifaceted disorders and, therefore, measurement of multiple outcomes is relevant to most of these diseases. Also, the complexity of the pathogenic processes underlying inflammatory rheumatic diseases leads to difficulty in finding a single representative outcome measure. Relevant areas of outcome measurement are disease activity, discomfort, disability, damage and death.

\section{Proxy outcomes}

Proxy outcomes are frequently used in rheumatology. Outcomes generally are manifestations reflecting the underlying pathogenic process, measures of discomfort, measures of disability, measures reflecting organ damage, and eventually death. Objectively measured organ damage probably is

Recent developments in outcome measures in the rheumatic diseases have been promoted by the development of

$\mathrm{ACR}=$ American College of Rheumatology; CDAI = Clinical Disease Activity Index; DAS = Disease Activity Score; DMARD $=$ disease-modifying antirheumatic drug; ESR = erythrocyte sedimentation rate; EULAR = European League Against Rheumatism; $\mathrm{HAQ}=\mathrm{Health}$ Assessment Questionnaire; OMERACT = Outcome Measures in RA Clinical Trials; RA = rheumatoid arthritis; RADAI = RA Disease Activity Index; RAPID = Routine Assessment of Patient Index Data; RCT = randomized, controlled trial; SDAI = Simplified Disease Activity Index; SF = Short Form. 
the best endpoint measure for rheumatic disorders. However, organ damage may take some time to complete and, quite notably, is a state to be prevented. Therefore, organ damage cannot always be used as an outcome measure, but instead it is inferred from precursors or the disease process supposedly leading to the damage. Biomarkers and technical imaging techniques are used to try to obtain a more precise measurement of the disease process and of damage, especially at subclinical levels of disease [2-4]. For example, in RA, bone edema made visible by imaging techniques may be regarded as a precursor of bone erosion [3].

\section{Disease activity}

In rheumatic disorders, the manifestations that are measured depend on the disease that is studied, and may comprise acute phase reactants, swollen and tender joint counts, pain, fatigue, morning stiffness, count of inflamed entheses, and so on. These manifestations comprise more or less objective signs (for example, counts of the number of swollen joints), naturally subjective symptoms (for example, pain, fatigue), and laboratory values (for example, erythrocyte sedimentation rate (ESR), and C-reactive protein levels). Disease activity in $\mathrm{RA}$ is a good example of where manifestations of the underlying pathogenic process have been combined in a pooled measure to increase its validity and precision (Table 1) [5]. The Disease Activity Score (DAS; and its modified version DAS28) consist of a combination of the number of tender joints, the number of swollen joints, ESR and a global assessment rating by the patient and are extensively validated [6]. The Simplified Disease Activity Index (SDAI) and the Clinical Disease Activity Index (CDAI) are derivations that omit the weighting (SDAI) and also omit a laboratory value (CDAI) [7].

The RA Disease Activity Index (RADAl) is a self-report questionnaire of symptoms, including a self-assessed joint count [8]. The Routine Assessment of Patient Index Data (RAPID) and the Patient Activity Scale (PAS) are patient selfreport questionnaires consisting of the three patient-reported outcomes of the core set of endpoints for RA clinical trials: pain, patient global assessment of disease activity, and the Health Assessment Questionnaire (HAQ) [9,10]. The RAPID may also include a RADAl-style self-rated joint count [9]. The DAS, DAS28, CDAI and SDAl include a single patient-rated item on global assessment.

\section{Discomfort and disability}

Symptoms of the disease may cause discomfort to the patient. In rheumatic diseases, pain and fatigue are important sources of discomfort that also lead to disability. Due to the involvement of the musculoskeletal system, disability obviously is a central concept in rheumatic disorders and there are many disorder-specific questionnaires available that measure the level of patient-perceived disability. The outstanding example of this is the disability index of the HAQ, which was developed for RA but is also applied in other rheumatic disorders [11,12]. Most emphasis is placed on 'patientreported outcomes' to measure patient-perceived disability.

\section{Damage}

Organ damage and death may be considered as 'hard' outcome measures in rheumatology. Progression of joint damage is a well-established outcome for trials in inflammatory joint diseases. In RA, measurement of joint damage of the hands and feet was deemed appropriate if trials last 12 months or longer, but with the current effective medication it may also be appropriate to measure joint damage after just 3 or 6 months. The eventual progression of joint damage can be rated by applying a standard scoring system, such as the Sharp-vanderHeijde score applied to plain X-rays of the hands and feet in RA [13]. The outcome measure can be the progression of raw scores or the number of patients that progress more than the smallest detectable change - for example, all patients that progress more than 6 points (Figure 1) [14]. Using the proportion of patients with progression of joint damage in two (treatment) groups favors the calculation of relative risk as an effect measure. Relative risks are easy to combine in meta-analyses.

\section{Death}

Mortality in RA was explored initially in 1953 and since then numerous other studies have investigated mortality among patients with RA, with most demonstrating reduced life expectancy ranging from 5 to 15 years compared with the general population $[15,16]$. In addition to RA, several other inflammatory rheumatic disorders are associated with increased mortality, notably psoriatic arthritis, and ankylosing spondylitis [16]. Rheumatic disorders infrequently appear as the cause of death on death certificates. Rather, what is regarded as the immediate cause of death, such as cardiovascular disease, renal failure or pulmonary infection, is noted. At least for RA it appears that mortality has not improved over time [17]. Observing improving trends of survival over calendar time in rheumatic disorders is an important outcome of the quality of rheumatology care for these patients. Death (survival time) may also be a relevant outcome for clinical trials that include patients who are treated for life-threatening complications of their rheumatic disorder [18].

\section{Quality of life}

Quality of life in the context of outcome measurement is generally handled as a descriptive term that refers to people's emotional, social and physical wellbeing, and their ability to function in the ordinary tasks of living. In arthritis, the most common used measure covering these items is the Short Form (SF)-36 questionnaire on general health, which has also been validated for RA [19]. The advantage of the SF-36 is that a broader concept of health is measured and the SF-36 can be compared across difference conditions. The term 'quality-of-life measures' is frequently used interchangeably with the term 'patient-reported outcomes'. However, instead of using the term 'quality-of-life', what can generally be 


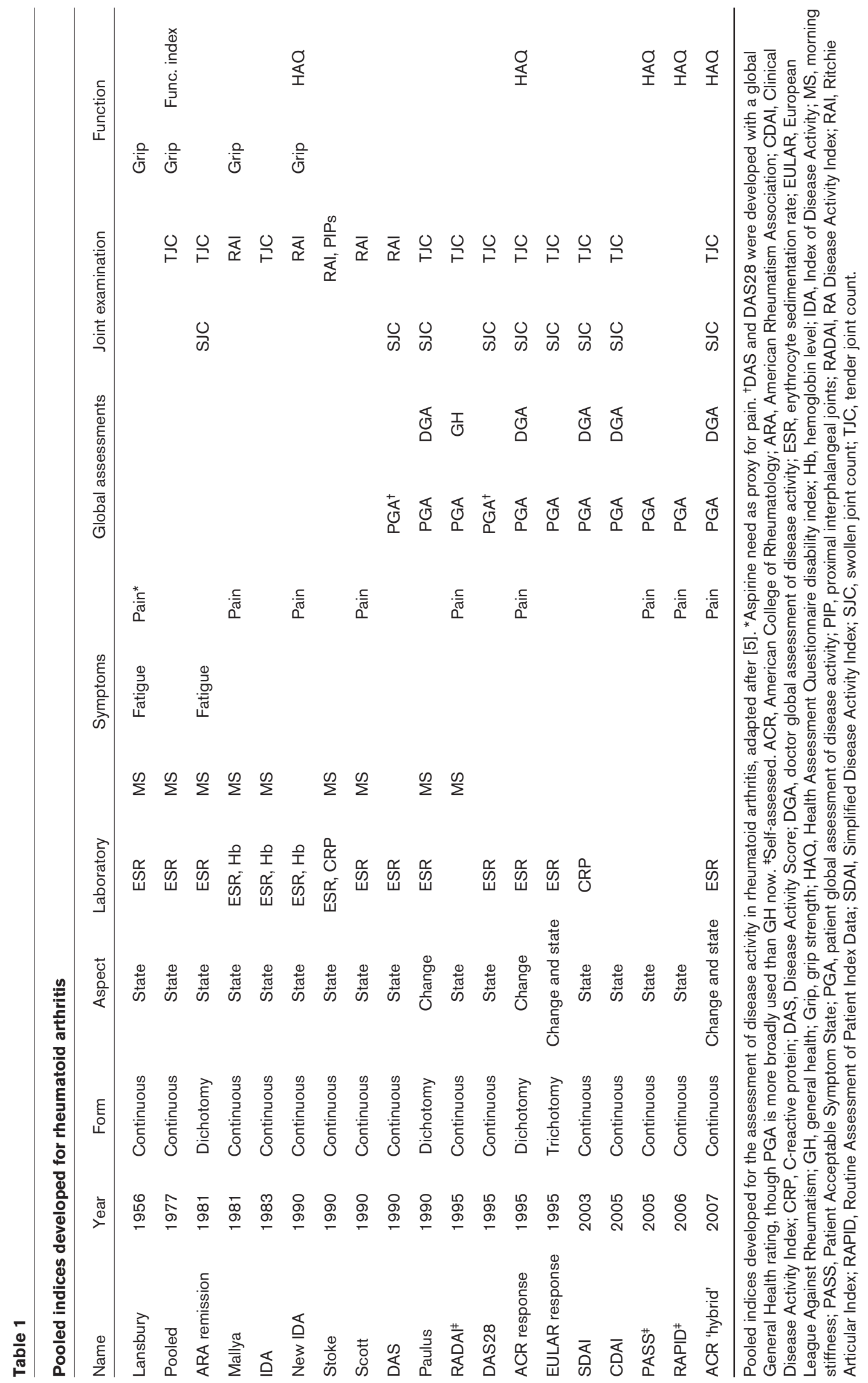


Figure 1

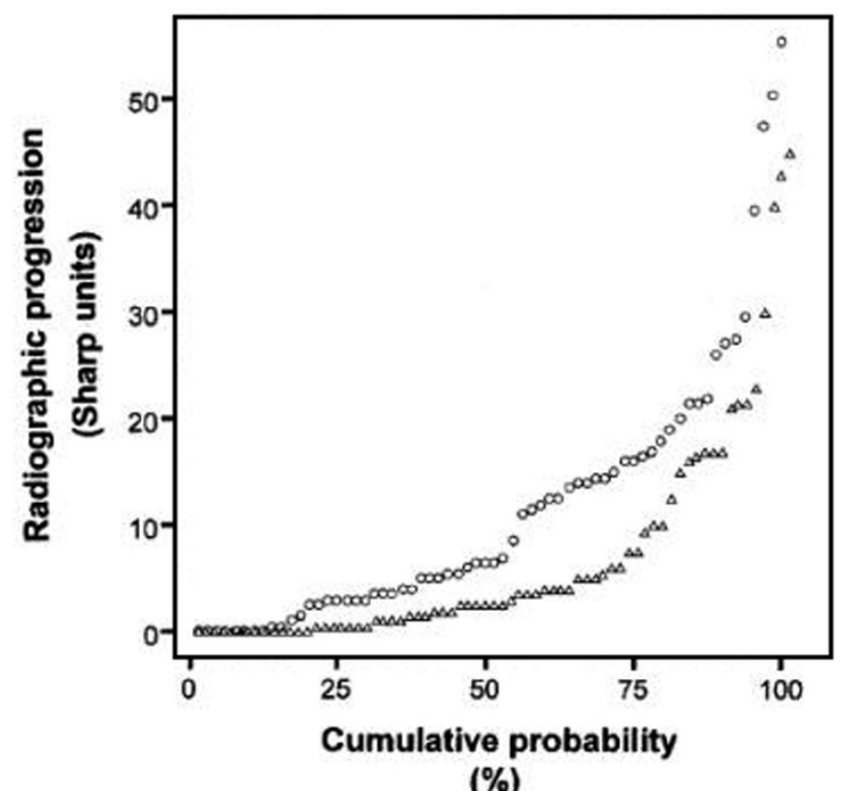

Cumulative probability plots of individual 1-year radiographic progression scores in 135 rheumatoid arthritis patients who were participating in the Combinatietherapie Bij Reumatoide Artritis (COBRA) trial (67 patients in the monotherapy group (circles) and 68 patients in the combination therapy group (triangles)). Reprinted from [14] with permission of John Wiley \& Sons, Inc.

described is what is measured: for example, emotional wellbeing, functioning, or disability. Satisfaction of a person with certain aspects of life, however, is a non-medical outcome and is not generally associated with a lasting influence of medical interventions.

\section{Outcome measures}

\section{Common outcome measures}

The use of core sets of outcome measures greatly enhanced the comparability of trials in rheumatic disorders. Because of the many manifestations involved in rheumatic disorders, there had been much variability in choice of trial endpoints and in the way they were measured. A process leading to consensus and standardization of outcome measures for trials was started for RA, notably by the Outcome Measures in RA Clinical Trials (OMERACT) initiative [20]. This agreed on the use of a 'core set' of measures to be used, at a minimum, in randomized, controlled trials (RCTs) on diseasemodifying antirheumatic drugs (DMARDs) in RA [20]. This core set comprises six measures representing joint inflammation, one measure of disability, and the measurement of joint damage in trials lasting 12 months or longer (Table 2). Physical disability or function is a key concept in rheumatic disorders. Several validated questionnaires to measure disability are available, but the most common questionnaire in clinical trials of RA and other rheumatic disorders is the HAQ.
Within the OMERACT framework, consensus on common outcome measures for other rheumatic disorders has also been attempted. Except for RA, similar approaches to establish core sets of measures, disease activity measures, and response criteria for RCTs have been made for several other rheumatic diseases, notably psoriatic arthritis and ankylosing spondylitis (Table 2) [20-23]. In contrast to RA, where the target organ system may be defined as the joints, these diseases have multiple manifestations in multiple organ systems; for example, manifestations of psoriatic arthritis may include arthritis, psoriasis, dactylitis, nail involvement, enthesitis, and spondylitis.

\section{Composite endpoint measures}

In the context of multiple outcome measures, and without a gold standard or obvious choice of measure to be used as primary outcome, composite endpoint measures are useful to avoid multiple testing and to increase statistical power. An advantage of the reduction of measurement error by combination of measures is that an index can be more responsive than its parts. The main disadvantages of composite measures are concerns over validity and practical problems such as interpretation and computational difficulties. The validity of an index depends on the validity of the measures that are included and their appropriate weighting. The interpretation of an index becomes easier when more information from validity studies (for example, discriminative or predictive) is available and when an index has become familiar. The composite indexes in use may fall in the categories of state measures and response measures.

\section{Assessment of state}

The most popular state index for use in RA is the DAS and its modified version DAS28 (Table 3) [24,25]. The DAS is a continuous measure reflecting the level of underlying rheumatoid inflammation. It was developed using decisions on DMARD therapy as an external standard of high and low disease activity. The DAS includes information from tender and swollen joint counts, ESR and a patient global rating, with the statistical advantage of having a Gaussian distribution.

The DAS28 is similar to the DAS, includes reduced joint counts and has a different range. The DAS28 ranges from 0 to 10: a DAS28 $\leq 3.2$ is equated with 'low' disease activity and a DAS28 $>5.1$ is called 'high' disease activity $[26,27]$.

Similar kinds of disease activity scores, in part using similar approaches, have been developed not only for RA (SDAI) and ankylosing spondylitis (Bath Ankylosing Spondylitis Disease Activity Index (BASDAI)), but also for systemic lupus erythematosus (Systemic Lupus Erythematosus Disease Activity Index (SLEDAI)), and systemic sclerosis [7,28-30].

\section{Assessment of change}

The two response measures most frequently used for testing DMARDs in RA are the European League Against Rheuma- 
Table 2

\begin{tabular}{lll}
\hline Core sets of trial outcome measures & & \\
\hline Rheumatoid arthritis & Psoriatic arthritis & Ankylosing spondylitis \\
\hline Acute phase reactants & Acute phase reactants & Acute phase reactants \\
Swollen joint count & Joint counts & Joint counts \\
Tender joint count & Axial skeleton & Enthesitis \\
Observer global rating & Observer global rating & Spinal mobility \\
Patient global rating & Dactylitis & Stiffness \\
Patient pain rating & Enthesitis & Patient global rating \\
Physical function & Psoriasis extent & Patient pain rating \\
Joint damage by X-ray & Nail involvement & Physical function \\
& Patient pain rating & \\
& Patient itching rating & \\
& Physical function & \\
\hline
\end{tabular}

Trial outcome measures deemed important for disease modifying anti-rheumatic therapies in rheumatoid arthritis [20,21], psoriatic arthritis [22], and ankylosing spondylitis [23].

Table 3

EULAR response criteria and the disease activity score in rheumatoid arthritis

\begin{tabular}{|c|c|c|c|c|c|}
\hline & & & \multicolumn{3}{|c|}{ Change in DAS or DAS28 attained } \\
\hline \multicolumn{3}{|c|}{ DAS or DAS28 attained at endpoint } & $>1.2$ & $0.6<\Delta \leq 1.2$ & $\leq 0.6$ \\
\hline 'High' & DAS $>3.7$ & DAS28 $>5.1$ & Moderate & & No \\
\hline 'Moderate' & $2.4<\mathrm{DAS} \leq 3.7$ & $3.2<$ DAS $28 \leq 5.1$ & Moderate & Moderate & \\
\hline 'Low’ & $\mathrm{DAS} \leq 2.4$ & DAS28 $\leq 3.2$ & Good & Moderate & \\
\hline
\end{tabular}

Calculation of the disease activity scores DAS and DAS28 to assess joint inflammation in rheumatoid arthritis and the response criteria of the European League against Rheumatism (EULAR) [24-27]. The EULAR criteria use the level of disease activity at the endpoint as well as the change at the endpoint for determining a patient as a good, moderate or non-responder. DAS28 $=0.56 \times(\sqrt{ } T \mathrm{JC} 28)+0.28 \times(\sqrt{ } \mathrm{SJC} 28)+0.70 \times(\mathrm{InESR})$ $+0.014 \times \mathrm{GH} ; \mathrm{DAS}=0.54 \times(\sqrt{\mathrm{RAI}})+0.065 \times \mathrm{SJC} 44+0.33 \times(\mathrm{InESR})+0.0072 \times \mathrm{GH}$. DAS, Disease Activity Score; ESR, erythrocyte sedimentation rate; GH, general health; RAI, Ritchie Articular Index; SJC, swollen joint count; TJC, tender joint count.

tism (EULAR) response criteria (Table 3) and the American College of Rheumatology (ACR) improvement criteria (Table 4) $[21,26]$. The ACR criteria are a dichotomized measure of change, whilst the EULAR criteria include change as well as the level of disease activity reached. Despite their different approaches, ACR and EULAR criteria generally lead to similar results [27]. The EULAR response criteria define the patient as a good, moderate or non-responder, dependent on both the magnitude of improvement according to the DAS or DAS28 and the absolute level of the DAS reached $[26,27]$. The ACR improvement criteria define a patient as a responder if there is at least $20 \%$ improvement in both tender and swollen joint counts, and in three of the following five measures: pain, patient global assessment, physician global assessment, disability, and an acute phase reactant [21]. The
ACR improvement criteria were designed to optimally discriminate placebo from drug in clinical trials. To accommodate the larger effects with newer medications, ACR50\% and $70 \%$ criteria are also used. However, these cut-off points are not endorsed as a primary outcome measure [32]. To accommodate testing differences between two effective medications that are generally smaller than a difference between placebo and a medication, a revised version of the ACR criteria ('ACR-hybrid') was developed [33].

Response criteria for use in RCTs have also been developed and applied in psoriatic arthritis (Psoriatic Arthritis Response Criteria (PsARC)), ankylosing spondylitis (Ankylosing Spondylitis Assessment Score (ASAS)) and osteoarthritis (Osteoarthritis Research Society International (OARSI)) [34-36]. 
Table 4

ACR improvement criteria for use in rheumatoid arthritis
A patient is classified as improved if there is at least $20 \%$ improvement
in five out of seven core-set variables, the first two required:
Tender joint count
Swollen joint count
Acute phase reactant
Patient rating of pain
Patient global assessment of disease activity
Observer global assessment of disease activity
Physical disability

$\mathrm{ACR}$, American College of Rheumatology.

\section{Outcome measurement in trials \\ Change or state measures?}

Currently, there is a movement from change endpoints to endpoints with absolute values. In contrast to change endpoints, when using absolute measures there is no need to choose cut-off points, and the difference between two drugs or between a drug and placebo can readily be interpreted in terms of the endpoint measure. Continuous measures are flexible for deriving other endpoints. Depending on what is considered appropriate, one could define in advance whether to use the absolute change in the measure, the percentage of patients below a cut-off point, time-to-reach that cut-off point, the number of visits below a cut-off point, and so on.

\section{Dichotomous or continuous endpoints?}

One of the advantages of dichotomized improvement criteria is that the outcome is clearly expressed as a yes or no response, or success or failure. This probably led to the dichotomization of originally continuous measures for use as trial endpoints, such as the 1.2 improvement in DAS28. The disadvantages of this approach include not only that power is lost when dichotomizing a continuous or ordinal measure, but also that meaning is lost.

The more attractive alternative would be to use the DAS as a continuous endpoint. If the underlying endpoint is continuous (disease activity, ability), a meaningful cut-off point should be chosen if dichotomizations are preferred. Examples of such outcome measures are the percentage of RA patients reaching low disease activity (DAS28 $\leq 3.2$ ), and the percentage of RA patients with a progression of joint damage larger than the smallest detectable change in X-ray score. Figure 1 illustrates an example where the smallest detectable change is determined as a 4-point change in the SharpvanderHeijde score [37]. This approach is especially appropriate if the outcome measure represents a target of treatment. A similar approach used for patient questionnaires is the definition of a minimal important change using patient panels. The percentage of patients exceeding this predefined minimal important change is used as the outcome measure.

An alternative that better reflects treatment goals is the concept of 'patient acceptable symptom state', which is also assessed using patient panels [38,39]. However, power is generally lost when dichotomizing a continuous measure. Therefore, it may be worthwhile to use a continuous measure as primary outcome, and use clinically useful dichotomizations as informative secondary outcomes.

\section{Minimal important change or remission?}

Reaching remission, or a state of low disease activity, is the ultimate goal of treatment in rheumatic disorders. Conceptually, remission is more appropriate than change as the endpoint. However, remission is not always a target that can be reached and a state of low disease activity could be used instead. A well-known example is the Minimal Disease Activity State (MDAS), which was developed for RA and can be calculated alternatively using the DAS28 or the ACR core-set measures [40].

The problem still is that remission is ill-defined and the absence of manifestations is difficult to measure. Also, it is unclear how far the underlying disease process is silent in the absence of manifestations. If minimal important change is used, information on the magnitude of change is lost and change does not reflect the target of treatment. The target is not to induce change per se, but rather change is necessary to reach the target of low disease activity or remission.

\section{Reporting of disease activity in trials}

Even with commonly used outcome measures, trial publications still differ in their reporting. Consequently, it is still difficult to compare trial results and to combine them in a meta-analysis. A recent initiative by the ACR and EULAR has provided recommendations on disease activity reporting in clinical trials [41]. If these recommendations are followed, it is warranted that similar and useful information can be derived from trial reports, irrespective of the primary outcome measure used. Important considerations are the reporting on disease activity response as well as states, and the inclusion of time (Table 5).

\section{Outcome measurement in practice}

In daily practice, outcomes should be measures of state rather than measures of change. The reason is that the goal of therapy is to reach low disease activity or even remission; thus, a physician should primarily know about the state the patient is in. A continuous measure of disease activity is most useful to measure changes (of the patient's state). Most available indices are subdivided into levels of 'low', 'moderate', and 'high' disease activity, analogous to the DAS and DAS28 (Table 3). However, states of remission or a 'patient acceptable symptom state' also provide meaningful endpoints in practice. 
Table 5

\section{EULAR/ACR collaborative recommendations for disease activity reporting in clinical trials}

\begin{tabular}{|c|c|}
\hline Point & Description \\
\hline 1 & Each trial should report the disease activity response and disease activity states \\
\hline $1 \mathrm{a}$ & $\begin{array}{l}\text { Response: ACR (ACR20, ACR50, ACR70: ideally also ACR Hybrid, after successful prospective validation in clinical trials) and } \\
\text { EULAR response criteria (good, moderate and non-responders) }\end{array}$ \\
\hline $1 b$ & $\begin{array}{l}\text { States: composite measures of disease activity should be used as outcome measures and with cut-off points to define various disease } \\
\text { activity states: they include DAS/DAS28, CDAl, and SDAl; appropriate descriptive statistics of the baseline, the endpoint and change } \\
\text { of the composite indices should be reported }\end{array}$ \\
\hline 2 & $\begin{array}{l}\text { Each trial should report the appropriate descriptive statistics of the baseline, the endpoint, and change of the single variables included } \\
\text { in the core set }\end{array}$ \\
\hline 3 & Each trial should report the baseline disease activity levels \\
\hline 4 & Each trial should report the percentage of patients achieving a low disease activity state and remission \\
\hline $4 a$ & $\begin{array}{l}\text { Definitions that should be used for low disease activity include cut-off points for low disease activity for DAS/DAS28, CDAl, SDAl, and } \\
\text { MDA }\end{array}$ \\
\hline $4 b$ & $\begin{array}{l}\text { Definitions that could be used for remission include preliminary ARA remission criteria and respective cut-off points for DAS/DAS28, } \\
\text { CDAI, and SDAI }\end{array}$ \\
\hline 5 & Each trial should report the time to onset of the primary outcome (a particular response or a certain disease activity state) \\
\hline 6 & $\begin{array}{l}\text { Each trial should consider and report the sustainability of the primary outcome (as opposed to evaluating it at a single predefined time } \\
\text { point during the trial) }\end{array}$ \\
\hline 7 & Each trial should report on fatigue \\
\hline
\end{tabular}

ACR, American College of Rheumatology; ARA, American Rheumatism Association; CDAl, Clinical Disease Activity Index; DAS, Disease Activity Score; EULAR, European League Against Rheumatism; MDA, Minimal Disease Activity; SDAI, Simplified Disease Activity Index. Reprinted from [41] with permission of John Wiley \& Sons, Inc.

General treatment principles in RA are that: patients who may have RA are to be detected and referred early, RA should be treated immediately, tight control of disease activity should be applied, and, in addition, treatment should be individually tailored considering risk-benefit [42]. These principles are reflected in treatment guidelines of the ACR and EULAR $[43,44]$.

In practice, outcome measurement is useful for treatment indication and for tight control. In the ACR recommendations for the use of nonbiologic and biologic DMARDs, the choice for treatment is steered by the presence of features of poor prognosis, disease activity, and disease duration [43]. As there currently are many appropriate disease activity indices available, it was considered that disease activity can be judged using the available definitions of 'low', 'moderate', and 'high' disease activity (Table 6).

Several trials have shown the beneficial effect of a tight control strategy in the treatment of RA, notably the Tight Control for Rheumatoid Arthritis (TICORA), Computer Assisted Management for Early Rheumatoid Arthritis (CAMERA), Treatment Strategies for RA (BeST) and Systematic Monitoring of RA Disease Activity (TRAC) studies [45-48]. There is also evidence to suggest that monitoring of disease activity without a treatment protocol confers no major improvement over usual care [48]. Therefore, the tight control principle can be understood as a protocol based on an objective measure of disease activity that determines whether treatment is escalated or reduced; a low threshold of continuing disease activity triggers a treatment change; and treatment decisions are made frequently (monthly rather than every 3 months) [42]. So far, disease activity indices, notably the DAS, have been used in tight control studies.

The RADAI and the RAPID are disease activity indices that are completely self-reported $[8,9]$. Self-report indices have the advantage that no laboratory values and no formal joint counts are required. However, many rheumatologists may be hesitant in omitting a joint count that is still seen as an important source of information. Regardless of the validated disease activity index used, adopting tight control principles may lead to a large benefit for patients in daily practice.

\section{Conclusions}

Inflammatory rheumatic diseases are generally diseases with variable presentation and, therefore, multiple outcomes are measured in most of these diseases. Because of the complexity of the pathogenesis underlying the diseases, multiple clinical manifestations are measured as a proxy for the pathogenic process. Beyond manifestations of the disease process, rheumatic diseases can have several different consequences, 
Table 6

\begin{tabular}{|c|c|c|c|c|}
\hline \multirow[b]{2}{*}{ Instrument } & \multirow[b]{2}{*}{ Range } & \multicolumn{3}{|c|}{ Thresholds of disease activity } \\
\hline & & Low & Moderate & High \\
\hline Disease Activity Score in 28 joints & 0 to 9.4 & $\leq 3.2$ & $>3.2$ and $\leq 5.1$ & $>5.1$ \\
\hline Simplified Disease Activity Index & 0.1 to 86.0 & $\leq 11$ & $>11$ and $\leq 26$ & $>26$ \\
\hline Clinical Disease Activity Index & 0 to 76 & $\leq 10$ & $>10$ and $\leq 22$ & $>22$ \\
\hline Rheumatoid Arthritis Disease Activity Index & 0 to 10 & $<2.2$ & $\geq 2.2$ and $\leq 4.9$ & $>4.9$ \\
\hline Patient Activity Scale & 0 to 10 & $<1.9$ & $\geq 1.9$ and $\leq 5.3$ & $>5.3$ \\
\hline Routine Assessment Patient Index Data & 0 to 30 & $<6$ & $\geq 6$ and $\leq 12$ & $>12$ \\
\hline
\end{tabular}

Reprinted from [43] with permission of John Wiley \& Sons, Inc.

making multiple outcomes relevant, including discomfort, disability, organ damage, and death; these may also include complications.

One of the challenges in facing multiple measurements is: should outcome measures be combined and, if yes, how? The development of pooled indices in RA is an outstanding example of this. Many developments in outcome measurement of rheumatic diseases started in RA and have been applied to other rheumatic diseases. However, in rheumatic diseases in which multiple organ systems are involved, such as psoriatic arthritis or systemic sclerosis, the combination of outcome measures is not straightforward. Developing outcome measures for diseases meeting new treatment targets will be of growing importance in the next decade.

In the next decade success of therapeutic strategies will be measured by the percentage of patients reaching remission or at least reaching a very low disease activity state, and not by how many patients improved by a certain amount. Indeed, for RA as well as other rheumatic diseases, the clinically most meaningful outcome measure is a state measure of disease activity, whilst the most efficient outcome measure for clinical trials is a continuous measure of change. Therefore, for clinical trials a continuous measure of change may be preferred as the primary outcome measure, and a measure of state may be preferred as the secondary outcome measure. It is an advantage when both the primary and secondary outcome measures are simply variations of the same measure, which should be meaningful in daily practice. In cohorts and in daily practice, state measures that can be converted to the same change measure as in trials are useful as the use of the same measures in trials, cohorts and practice promotes knowledge transfer.

Following treatment success in RA, the vision of pharmacological treatment in the inflammatory rheumatic diseases nowadays has become reaching and sustaining remission. Clinical remission, meaning absence of clinically visible

\section{The Scientific Basis of Rheumatology: A Decade of Progress}

This article is part of a special collection of reviews, The Scientific Basis of Rheumatology: A Decade of Progress, published to mark Arthritis Research \& Therapy's 10th anniversary.

Other articles in this series can be found at: http://arthritis-research.com/sbr

disease manifestations, including the condition that disease consequences do not occur, may be a reasonable target for a start. When disease manifestations are reduced to subclinical levels, this raises additional interest in biomarkers and imaging techniques for outcome measurement. Finding biomarkers and imaging techniques that are suited for use in daily clinical practice will become even more important. However, for daily clinical practice, outcome measures should be feasible and meaningful: feasible to perform in busy daily clinical practice, and meaningful to be able to steer treatment decisions. At this point, patient-reported outcomes and easily derivable clinical indices have an advantage in this regard.

\section{Competing interests}

PLCMvR had a major role in developing the DAS, DAS28 and EULAR response criteria. The authors declare that they have no other competing interests.

\section{References}

1. Felson DT: Assessing the efficacy and safety of rheumatic disease treatments. Arthritis Rheum 2003, 48:1781-1787.

2. Farrant JM, O'Connor PJ, Grainger AJ: Advanced imaging in rheumatoid arthritis. Part 1: synovitis. Skeletal Radiol 2007, 36: 269-279. 
3. Farrant JM, Grainger $\mathrm{AJ}, \mathrm{O}^{\prime}$ Connor PJ: Advanced imaging in rheumatoid arthritis. Part 2: erosions. Skeletal Radiol 2007, 36: 381-389.

4. Emery P, Gabay C, Kraan M, Gomez-Reino J: Evidence-based review of biologic markers as indicators of disease progression and remission in rheumatoid arthritis. Rheum Int 2007, 27:793-806.

5. Boers M, Tugwell P: The validity of pooled outcome measure (indices) in rheumatoid arthritis clinical trials. J Rheumatol 1993, 20:568-574.

6. Fransen J, Stucki G, Van Riel PLCM: Rheumatoid arthritis measures. Arthritis Rheum 2003, 49(5S):S214-224.

7. Aletaha D, Smolen J: The Simplified Disease Activity Index (SDAI) and the Clinical Disease Activity Index (CDAI): a review of their usefulness and validity in rheumatoid arthritis. Clin Exp Rheumatol 2005, 23(5 Suppl 39):S100-108.

8. Stucki G, Liang MH, Stucki S, Brühlmann P, Michel BA: A selfadministered rheumatoid arthritis disease activity index (RADAI) for epidemiologic research. Psychometric properties and correlation with parameters of disease activity. Arthritis Rheum 1995, 38:795-798.

9. Pincus $T$, Yazici $Y$, Bergman $M$, Swearingen $C$, Harrington $T$ : A proposed approach to recognise 'near remission' quantitatively without formal joint counts or laboratory tests: a patient self-report questionnaire Routine Assessment Of Patient Index Data (RAPID) score as a guide to a "continuous quality improvement'. Clin Exp Rheumatol 2006, 24(6 Suppl 43):S-6065; quiz S-66-73.

10. Wolfe $F$, Michaud $K$, Pincus $T$ : A composite disease activity scale for clinical practice, observational studies, and clinical trials: the Patient Activity Scale (PAS/PAS-II). J Rheumatol 2005, 32:2410-2415.

11. Fries JF, Spitz $P$, Kraines RG, Holman HR: Measurement of patient outcome in arthritis. Arthritis Rheum 1980, 23:137-145.

12. Bruce B, Fries JF: The Health Assessment Questionnaire (HAQ). Clin Exp Rheum 2005, 23(5)Suppl 39):S14-18t.

13. Van der Heijde D: How to read radiographs according to the Sharp/van der Heijde method. J Rheumato/ 2000, 27:261-263.

14. Landewe $R$, Van der Heijde $D$ : Radiographic progression depicted by probability plots: presenting data with optimal use of individual values. Arthritis Rheum 2004, 50:699-706.

15. Cobb S, Anderson F, Bauer W: Length of life and cause of death in rheumatoid arthritis. N Engl J Med 1953, 249:553556.

16. Sokka T, Pincus T: Mortality in the rheumatic diseases. Introduction. Clin Exp Rheumatol 2008, 26(Suppl 51):S1-4.

17. Boers M, Dijkmans B, Gabriel S, Maradit-Kremers H, O'Dell J, Pincus T: Making an impact on mortality in rheumatoid arthritis. Targeting cardiovascular comorbidity. Arthritis Rheum 2004, 50:1734-1739.

18. Wong WK, Furst DE, Clements PJ, Streisand JB: Assessing disease progression using a composite endpoint. Stat Meth Med Res 2007, 16:31-49.

19. Kosinski M, Keller SD, Hatoum HT, Kong SX, Ware JE Jr: The SF36 Health Survey as a generic outcome measure in clinical trials of patients with osteoarthritis and rheumatoid arthritis: tests of data quality, scaling assumptions and score reliability. Med Care 1999, 37(5 Suppl):MS10-22.

20. Tugwell $P$, Boers $M$ : Developing consensus on preliminary core efficacy endpoints for rheumatoid arthritis clinical trials. OMERACT Committee. J Rheumatol 1993, 20:555-556.

21. Felson DT, Anderson JJ, Boers M, Bombardier C, Furst D, Goldsmith C, Katz LM, Lightfoot R Jr, Paulus H, Strand V, et al.: American College of Rheumatology. Preliminary definition of improvement in rheumatoid arthritis. Arthritis Rheum 1995, 38: 727-735.

22. Gladman D: Consensus exercise on domains in psoriatic arthritis. Ann Rheum Dis 2005, 64(Suppl 2):ii113-4.

23. van der Heijde D, Bellamy N, Calin A, Dougados M, Khan MA, van der Linden S: Assessments in Ankylosing Spondylitis Working Group. Preliminary core sets for endpoints in ankylosing spondylitis. J Rheumatol 1997, 24:2225-2229.

24. van der Heijde DM, van 't Hof MA, van Riel PL, Theunisse LA, Lubberts EW, van Leeuwen MA, van Rijswijk MH, van de Putte LB: Judging disease activity in clinical practice in rheumatoid arthritis: first step in the development of a disease activity score. Ann Rheum Dis 1990, 49:916-920.
25. Prevoo MLL, Van 't Hof MA, Kuper HH, Van Leeuwen MA, Van de Putte LBA, Van Riel PLCM: Modified disease activity scores that include twenty-eight-joint counts. Development and validation in a prospective longitudinal study of patients with rheumatoid arthritis. Arthritis Rheum 1995, 38:44-48.

26. van Gestel $A M$, Prevoo ML, van 't Hof MA, van Rijswijk $M H$, van de Putte LB, van Riel PL: Development and validation of the European League Against Rheumatism response criteria for rheumatoid arthritis. Arthritis Rheum 1996, 39:34-40.

27. Van Gestel AM, Haagsma CJ, Van Riel PLCM: Validation of rheumatoid arthritis improvement criteria that include simplified joint counts. Arthritis Rheum 1998, 41:1845-1850.

28. Smolen JS, Breedveld FC, Schiff MH, Kalden JR, Emery P, Eberl G, van Riel PL, Tugwell P: A simplified disease activity index for rheumatoid arthritis for use in clinical practice. Rheumatology 2003, 42:244-257.

29. Garrett $S$, Jenkinson T, Kennedy LG, Whitelock H, Gaisford $P$ Calin A: A new approach to defining disease status in ankylosing spondylitis: the Bath Ankylosing Spondylitis Disease Activity Index. J Rheumatol 1994, 21:2286-2291.

30. Bombardier C, Gladman DD, Urowitz MB, Caron D, Chang $\mathrm{CH}$ : Derivation of the SLEDAI. A disease activity index for lupus patients. The Committee on Prognosis Studies in SLE. Arthritis Rheum 1992, 35:630-640.

31. van Gestel AM, Anderson JJ, van Riel PL, Boers M, Haagsma CJ, Rich B, Wells G, Lange ML, Felson DT: ACR and EULAR improvement criteria have comparable validity in rheumatoid arthritis trials. J Rheumatol 1999, 26:705-711.

32. Felson DT, Anderson JJ, Lange ML, Wells G, LaValley MP: Should improvement in rheumatoid arthritis clinical trials be defined as fifty percent or seventy percent improvement in core set measures, rather then twenty percent? Arthritis Rheum 1998, 41:1564-1570.

33. American College of Rheumatology Committee to Reevaluate Improvement Criteria: A proposed revision to the ACR20: the hybrid measure of American College of Rheumatology response. Arthritis Rheum 2007, 57:193-202.

34. Clegg DO, Reda DJ, Mejias E, Cannon GW, Weisman MH, Taylor T, Budiman-Mak E, Blackburn WD, Vasey FB, Mahowald ML, Cush JJ, Schumacher HR Jr, Silverman SL, Alepa FP, Luggen ME, Cohen MR, Makkena R, Haakenson CM, Ward RH, Manaster BJ, Anderson RJ, Ward JR, Henderson WG: Comparison of sulfasalazine and placebo in the treatment of psoriatic arthritis. Arthritis Rheum 1996, 39:2013-2020.

35. Anderson JJ, Baron G, van der Heijde D, Felson DT, Dougados M: Ankylosing spondylitis assesment group preliminary definition of short-term inprovement in ankylosing spondylitis. Arthritis Rheum 2001, 44:1876-1886.

36. Pham T, van der Heijde D, Altman RD, Anderson JJ, Bellamy N, Hochberg M, Simon L, Strand V, Woodworth T, Dougados M: OMERACT-OARSI initiative: Osteoarthritis Research Society International set of responder criteria for osteoarthritis clinical trials revisited. Osteoarthritis Cartilage 2004, 12:389-399.

37. Bruynesteyn K, Boers M, Kostense P, van der Linden S, van der Heijde D: Deciding on progression of joint damage in paired films of individual patients: smallest detectable difference or change. Ann Rheum Dis 2005, 64:179-182.

38. Tubach F, Dougados M, Falissard B, Baron G, Logeart I, Ravaud $P$ : Feeling good rather than feeling better matters more to patients. Arthritis Rheum 2006, 55:526-530.

39. Tubach F, Ravaud $P$, Beaton $D$, Boers $M$, Bombardier $C$, Felson DT, van der Heijde D, Wells G, Dougados M: Minimal clinically important improvement and patient acceptable symptom state for subjective outcome measures in rheumatic disorders. J Rheum 2007, 34:1188-1193.

40. Wells GA, Boers M, Shea B, Brooks PM, Simon LS, Strand CV, Aletaha D, Anderson JJ, Bombardier C, Dougados M, Emery P, Felson DT, Fransen J, Furst DE, Hazes JM, Johnson KR, Kirwan JR, Landewé RB, Lassere MN, Michaud K, Suarez-Almazor M, Silman AJ, Smolen JS, Van der Heijde DM, van Riel PL, Wolfe F, Tugwell PS: Minimal disease activity for rheumatoid arthritis: a preliminary definition. J Rheum 20005, 32:2016-2024.

41. Aletaha D, Landewe R, Karonitsch T, Bathon J, Boers M, Bombardier C, Bombardieri S, Choi H, Combe B, Dougados M, Emery P, Gomez-Reino J, Keystone E, Koch G, Kvien TK, Martin-Mola E, Matucci-Cerinic M, Michaud K, O'Dell J, Paulus H, Pincus T, Richards P, Simon L, Siegel J, Smolen JS, Sokka T, Strand V, 
Tugwell $\mathrm{P}$, van der Heijde $\mathrm{D}$, van Riel $\mathrm{P}$, et al.: Reporting disease activity in clinical trials of patients with rheumatoid arthritis: EULAR/ACR collaborative recommendations. Arthritis Rheum 2008, 59:1371-1317.

42. Kiely PD, Brown AK, Edwards CJ, O'Reilly DT, Ostör AJ, Quinn M, Taggart A, Taylor PC, Wakefield RJ, Conaghan PG: Contemporary treatment principles for early rheumatoid arthritis: a consensus statement. Rheumatology 2009, 48:765-772.

43. Saag KG, Teng GG, Patkar NM, Anuntiyo J, Finney C, Curtis JR, Paulus HE, Mudano A, Pisu M, Elkins-Melton M, Outman R, Allison JJ, Suarez Almazor M, Bridges SL Jr, Chatham WW, Hochberg M, MacLean C, Mikuls T, Moreland LW, O'Dell J, Turkiewicz AM, Furst DE; American College of Rheumatology: American College of Rheumatology 2008 Recommendations for the use of nonbiologic and biologic disease-modifying antirheumatic drugs in rheumatoid arthritis. Arthritis Rheum 2008, 59:762-784.

44. Combe B, Landewe R, Lukas C, Bolosiu HD, Breedveld F, Dougados M, Emery P, Ferraccioli G, Hazes JM, Klareskog L, Machold K, Martin-Mola E, Nielsen H, Silman A, Smolen J, Yazici H: EULAR recommendations for the management of early arthritis: Report of a task force of the European Standing Committee for International Clinical Studies Including Therapeutics (ESCISIT). Ann Rheum Dis 2007, 66:34-45.

45. Grigor C, Capell H, Stirling A, McMahon AD, Lock P, Vallance R, Kincaid W, Porter D: Effect of a treatment strategy of tight control for rheumatoid arthritis (the TICORA study): a singleblind randomised controlled trial. Lancet 2004, 364:263-269.

46. Verstappen SM, Jacobs JW, van der Veen MJ, Heurkens $A H$, Schenk Y, ter Borg EJ, Blaauw AA, Bijlsma JW; Utrecht Rheumatoid Arthritis Cohort study group: Intensive treatment with methotrexate in early rheumatoid arthritis: aiming for remission. Computer Assisted Management in Early Rheumatoid Arthritis (CAMERA, an open-label strategy trial). Ann Rheum Dis 2007, 66:1443-1449.

47. Goekoop-Ruiterman YP, de Vries-Bouwstra JK, Kerstens PJ, Nielen MM, Vos K, van Schaardenburg D, Speyer I, Seys PE, Breedveld FC, Allaart CF, Dijkmans BA: DAS-driven therapy versus routine care in patients with recent-onset active rheumatoid arthritis. Ann Rheum Dis 2009 [Epub ahead of print].

48. Fransen J, Moens HB, Speyer I, van Riel PL: Effectiveness of systematic monitoring of rheumatoid arthritis disease activity in daily practice: a multicentre, cluster randomised controlled trial. Ann Rheum Dis 2005, 64:1294-1298 